\title{
Lesões osteoarticulares em frangos de corte de microrregião do Estado de São Paulo
}

\author{
Osteo articulars lesions on broilers in a certain country of \\ São Paulo State
}

\author{
Lúcia Alvariz Severo da Costa, ${ }^{*}$ Paulo Soares da Costa, ${ }^{\star \star}$ Eulógio Carlos Queiroz de Carvalho, ${ }^{\star \star \star}$ \\ Carlos Wilson Gomes Lopes ${ }^{\star \star \star \star}$
}

\begin{abstract}
Resumo
As lesões osteoarticulares têm etiologia complexa, pois vários fatores as provocam, tais como manejo inadequado, genética dos plantéis e controle sanitário deficiente. A ocorrência de lesões osteoarticulares provocam condenações parciais ou totais de carcaças, implicando perdas econômicas, pela atuação da inspeção sanitária. Numa região do Estado de São Paulo, foram colhidas 67 amostras de ossos e articulações, sendo processadas histologicamente 31. As amostras foram colhidas de acordo com a macroscopia e a patologia suspeitada, encontrando-se duas com deformação "valgus", 27 com quadro típico de contusão (hemorragia, congestão e edema), indicativo de tecnopatia; sendo sete na tíbia e vinte no fêmur e, duas amostras de tíbias negativas.
\end{abstract}

Palavras-chave: frango; lesões osteoarticulares; inspeção.

\section{Abstract}

The osteo-articulars lesions have complex ethiology because many agents induce them such as incorrect handling, genetic and inefficient sanitary control. The occurrence of osteo-articulars lesions induce parcial or total carcasses condemnation by sanitary inspection.

In São Paulo state on a certain country were collected 67 (sixty-seven) bones and joints samples but only 31 (thirty-one) were histologically processed. On this experiment the samples were collected occording to the macroscopic aspects and suspect pathology, finding 02 (two) with "valgus" deformation, 27 (twenty-seven) typically like contusions (hemorhage, congestion and edemas), indicating technopathy, were 07 (seven) in tibia and 20 (twenty) in femur and, 02 (two) tibia samples were negative.

Keywords: broiler; osteo-articulars; lesions; inspection.

\section{Introdução}

Atualmente, $O$ abate de frangos sob a Inspeção Federal beira a cifra de 3 bilhões de cabeças/ano e as perdas por lesões ósseas são significantes. As condenações por problemas ósseos atingem 0,5 a $1,0 \%$ dos frangos produzidos no Brasil. No entanto, poucos levantamentos detalhados são encontrados na literatura quantificando esses prejuízos (Tardin, 1995). Assim sendo, doenças não-infecciosas do sistema musculoesquelético são indicadas como importantes causas de lesões nas pernas de frangos, e a etiologia de algumas delas é pouco entendida (Riddell et al., 1983).

Tradicionalmente, os problemas do sistema locomotor das aves são descritos como "debilidade das patas". O termo abrange uma ampla gama de anomalias, mas não distingue entre transtornos músculo-esqueléticos e nervosos e não proporciona informação quanto a sua etiologia ou patologia (Thorp, 1994). "Em verdade, os estudos dos problemas ósseos em Gallus gallus domesticus têm sido prejudicados pela insuficiência de dados histológicos" (Coelho, 1982).

Segundo Summers et al., (1984), as anomalias nas pernas das aves na sua maioria não são devidas a uma simples deficiência nutricional, nem a um fator ambiental. O problema para esses autores é complexo. A literatura que enfoca o processamento de frangos de corte aponta também a importância das denominadas "tecnopatias" causadoras de contusões e fraturas nos membros das aves.

Sobressaem na literatura consultada os trabalhos referentes à discondroplasia tibial. Esta lesão foi pela primeira vez descrita experimentalmente em frangos em 1965 (Leach e Neshein, apud Bartels et al., 1989, p. 254).

* Empresa de Pesquisa Agropecuária do Estado do Rio de Janeiro (PESAGRO / Rio) - Niterói - RJ - CEP 24000-000.

** Serviço de Inspeção Federal do Ministério da Agricultura. Professor Adjunto do Departamento de Tecnologia dos Alimentos da Faculdade de Veterinária da UFF - Niterói - RJ - CEP 24230-340.

*** Professor Titular e Chefe do Setor de Patologia Veterinária Professor Jefferson Andrade dos Santos / UFF, da Faculdade de Veterinária da UFF - Niterói - RJ - CEP 24230-340.

**** Professor Titular de Parasitologia Veterinária - Instituto de Biologia - Universidade Federal Rural do Rio de Janeiro - Seropédica - RJ - CEP 23851-970. 
Para Leeson e Summers (1988), assim como para Riddel (apud Zhang et al., 1996, p. 691), essa é a anomalia mais comum em frangos de corte.

Outra lesão de importância na produção de frangos de corte é a denominada "pernas torcidas". Este termo foi, segundo Osbaldiston (apud Julian, 1984, p. 255), usado por ele pela primeira vez em 1967, para se referir a um desvio lateral ou medial do eixo da tíbia, sendo posteriormente usado para uma variedade muito grande de deformações ósseas.

Para esta lesão, o autor sugeriu o uso do termo específico "deformação valgus-varus" da articulação tíbio-tarsiana, ao invés de "pernas torcidas" e, osteodistrofia, que é inespecífico, para referir-se a qualquer formação defeituosa de osso (Osol et al., 1982, Newbrey et al., 1988).

De acordo com Julian (1984), exames macro e microscópico dos ossos, não revelaram lesões na cartilagem articular e, no exame radiológico, observou-se um espessamento da córtex, porém parecendo ser um efeito e não uma causa do desvio.

Riddell (apud Fallavena, 1984, p. 6) afirma que, dentre as causas de deformações de pernas de frangos de corte, a discondroplasia tibial e a deformação valgus-varus parecem ser as mais importantes, haja vista a elevada freqüência com que ocorrem na indústria avícola. A degeneração da cabeça do fêmur também é relatada como causadora de problemas na perna de frangos, mas não tem sido descrita em detalhes (Rieddell et al., 1983).

Segundo Grossklaus (1979), as tecnopatias carecem geralmente de importância para a higiene da carne, a não ser que repercutam sobre a qualidade do produto.

De acordo com Mulder (1994), são considerados pontos críticos de controle, as condições em que as aves são apanhadas, transportadas e retiradas dos engradados antes de serem abatidas. Por exemplo, um intenso batimento de asas durante a "apanha" contribui para uma condição anormal da carcaça como contusão e/ou hemorragia de ponta de asa. Estas condições resultam numa desvalorização da carcaça de frango e na necessidade de uma toilette que leva a uma substancial perda econômica (Kannan e Mench, 1996).

O estudo microscópico de lesões osteoarticulares de partes de frango, como coxa e sobrecoxa, que acarretam condenações pela Inspeção Sanitária com as conseqüentes perdas econômicas, é revelado nesta investigação.

\section{Material e métodos}

As 67 amostras foram colhidas em duas etapas. A primeira numa granja, acompanhando-se o manejo. Esta se localizava no município de Descalvado, Estado de São Paulo.

Os lotes destinados ao abate constituíam-se de 40.030 frangos de ambos os sexos, com peso médio vivo de $2,30 \mathrm{~kg}$ e 47 dias de idade distribuídos em vários galpões.

A segunda etapa se deu na linha de inspeção post-mortem "C", onde funcionários da inspeção federal local são responsáveis pelo exame da parte externa da carcaça, incluindo pele e articulações. Nesta linha, efetua-se a remoção de contusões e fraturas.

Das carcaças condenadas total ou parcialmente, por apresentarem lesões osteoarticulares e na pele, colheram-se ao acaso 25 amostras, sendo 10 de tíbia, com suas respectivas articulações tíbio-tarsianas correspondentes ao corte técnico de coxa, e 15 de fêmur, correspondentes ao corte técnico de sobrecoxa, que apresentavam lesões mais acentuadas de contusões e hemorragias.

Outra atividade desenvolvida foi a de acompanhar os trabalhos executados na "sala de cortes", local onde as carcaças são recortadas nos vários cortes comerciais.

Deste setor, foram colhidas 40 amostras, sendo 20 de tíbia (coxa) e 20 de fêmur (sobrecoxa), escolhidas também aleatoriamente dentre as peças descartadas pela empresa, cujas lesões não foram detectadas em nível de inspeção de linha post-mortem " $\mathrm{C}$ ".

As 65 amostras de ossos e cartilagens colhidas no matadouro, mais as duas de tíbia com suas articulações, provenientes de aves na própria granja, foram acondicionadas em vidros com tampa rosqueada contendo solução de formol a 10\%. Destas, 31 estavam em condições apropriadas para a histotécnica.

Para o estudo histopatológico, o material foi processado no Laboratório do Serviço de Patologia Veterinária "Professor Jefferson Andrade dos Santos", da Disciplina de Anatomia Patológica Veterinária, do Departamento de Patologia da Faculdade de Veterinária da Universidade Federal Fluminense (UFF), em Niterói - RJ.

As peças ósseas fixadas em solução aquosa de formol a $10 \%$ foram descalcificadas em solução de ácido nítrico a $7,5 \%$ por 4 dias.

Após a descalcificação e clivagem, os fragmentos foram submetidos a processamento por inclusão em parafina e coloração por HE.

A microscopia foi realizada com registro fotomicrográfico em aparelho Wild Leitz Universal equipado com "Photoautomaut MPS 55".

\section{Resultados}

As amostras foram colhidas de acordo com a macroscopia e a patologia suspeitada que, após processadas, apresentaram os resultados a seguir sumariados:

Das 31 amostras, duas apresentaram deformação valgus, 27 quadro típico de contusão (hemorragia, congestão e edema), indicativo de tecnopatia, sendo sete na tíbia e 20 no fêmur e duas amostras de tíbia negativas.

As lesões tíbio-metatarsianas, duas espécimes colhidas na granja, com 18 e 34 dias de idade, revelaram desvio medial da extremidade distal do tibiotarso, resultando num desvio para fora do tarsometatarso, unilateral. Deformação valgus. A descrição microscópica não teve expressão. Os achados são próprios de deformação valgus (constitucional/macro).

As tíbias e articulações tíbio-metatarsianas (correspondente à coxa), em número de sete espécimes, com 47 dias de idade, mostraram a porção distal da tíbia (coxa), com um edema gelatinoso e aspecto hemorrágico, moderado e com formação de coágulos subcutâneos, algumas vezes, exibindo áreas esverdeadas comprometendo o tecido subcutâneo e musculatura e também deslocamento de cápsula articular. A microscopia mostrou alterações circulatórias periarticulares, como: hemorragia, congestão e edema variados em intensidade (Figura 1). 


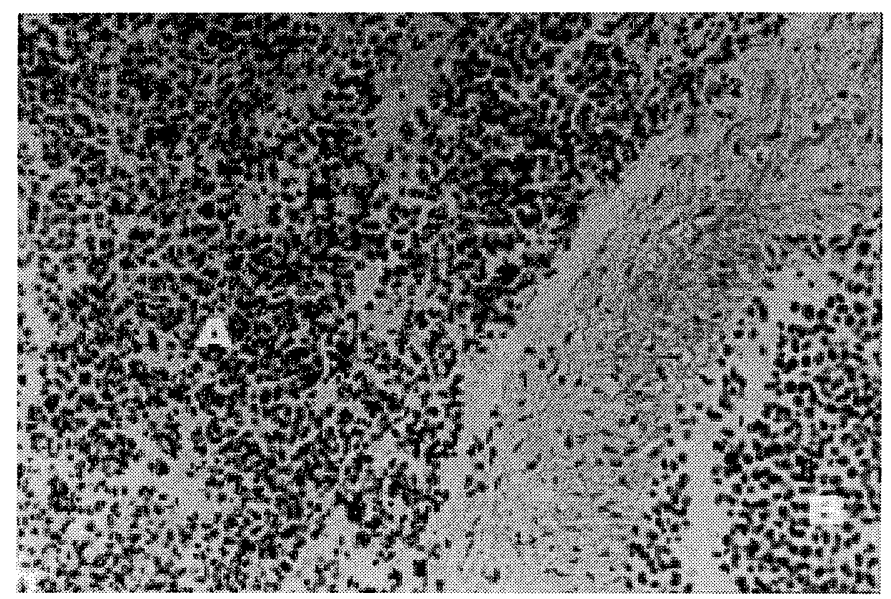

Figura 1: Articulação / Frango. Região periarticular tomada maciçamente por hemorragia (A) e congestão (B). H.E. $400 \mathrm{X}$

Os fêmures e articulações coxo-femurais (correspondente à sobrecoxa), em número de 20 espécimes, com 47 dias de idade, mostraram cabeça do fêmur apresentando um pronunciado processo de hemartrose com deslocamento da cápsula articular. Tecidos moles perarticulares, com aparente distúrbio circulatório (congestivo-hemorrágico e edema) de intensidade variada. Ao microscópio havia regularidade da arquitetura tecidual da cápsula articular, osso epifisário e disco. O tecido mole periarticular exibiu hemorragias, congestão e edema, todos em graus variados de gravidade (Figura 2). Concluiu-se, neste grupo, o diagnóstico de distúrbios circulatórios periarticulares (hemorragia, congestão e edema) variados em intensidade.

As tíbias (coxas), em número de duas espécimes de frangos com 47 dias de idade, revelaram engrossamento das porções proximais e fraturas. A microscopia não mostrou alterações significativas.

\section{Discussãó}

Foi notável no levantamento da literatura especializada, o grande número de trabalhos referentes à discondroplasia tibial que, no princípio, nos levou a pensar que este achado se daria com certa facilidade, o que não ocorreu.

O nosso resultado histopatológico é consoante com os de Julian (1984), no sentido de que não houve nenhuma lesão digna de expressão, senão os distúrbios circulatórios decorrentes de "tecnopatias".

\section{Referências bibliográficas}

BARTELS, J.E., McDANIEL, G.R., HOERR, F.J. Radiographic Diagnosis of Tibial Dyscondroplasia in Broiler a Field Selection Technique. Avian Diseases, Kennett Square, v. 33, n. 2, p. 254-257, abr./ jun., 1989.

COELHO, H.E. Crescimento Ósseo Endocondral em Frango de Corte. Belo Horizonte, 1982. 32 p. Tese (Mestrado em Medicina Veterinária) - Universidade Federal de Minas Gerais.

FALLAVENA, L.C.B. Alterações ósseas em frangos de sete linhagens do tipo corte comercializadas no Brasil: estudo clínico e morfológico. Belo Horizonte, 1984, 41 p. Tese (Mestrado em Medicina Veterinária) - Universidade Federal de Minas Gerais.
Nenhum trabalho sobre degeneração da cabeça do fêmur foi levantado no período compreendido por esta pesquisa, o que vem ao encontro com a afirmação de Riddell et al. (1983).

Em relação às tecnopatias, contrariamos Grossklaus (1979), já que nestes achados observou-se hemorragia, o que, por si só, nos indica a importância das mesmas para a higiene e qualidade do produto, uma vez que o sangue é um excelente meio de cultura, sem contar as condenações por elas provocadas.

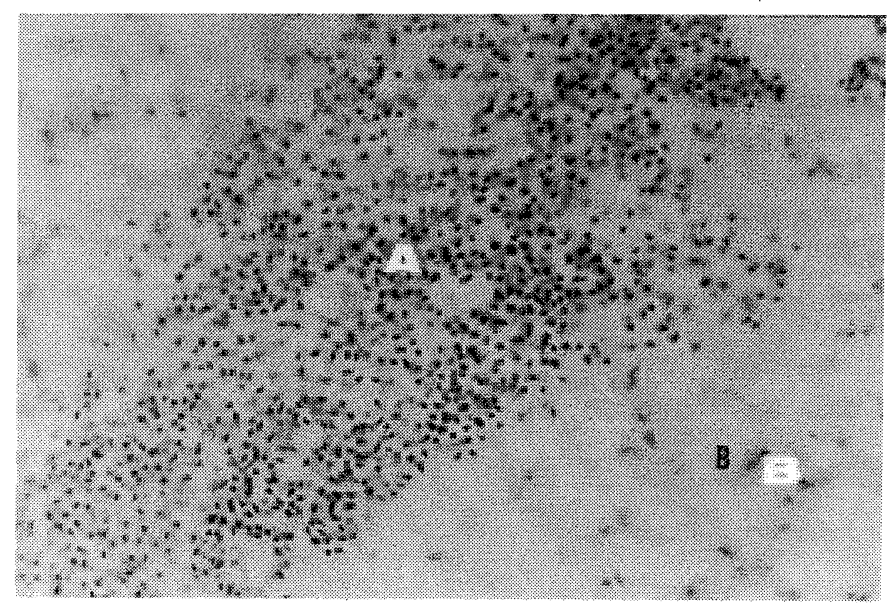

Figura 2: Articulação / Frango. Hemorragia moderada (A) e edema discreto em meio ao tecido adiposo de região periarticular (B). H.E. $400 \mathrm{X}$

A voltagem usada na insensibilização dos frangos no presente estudo foi de 50 Volts e freqüências de $1.000 \mathrm{Hertz}$, proporcionando bom atordoamento, o que nos leva a comprovar que as lesões por nós encontradas foram causadas durante a "apanha", carregamento e descarregamento dos engradados, confirmando Gregory e Wilkins. (1990), sendo ainda justificadas quando amostras de fêmur enviadas ao laboratório apresentaram deslocamento da cápsula articular, o que coincide com os achados desses autores em casos de contusão. As tecnopatias, nas diversas fases que antecedem a insensibillização, foram as responsáveis por lesões ósseas nos membros dos frangos de corte abatidos, principalmente nas pernas, provocando condenação total ou parcial dos mesmos com conseqüentes prejuízos econômicos aos produtores.

GREGORY, N.G. e WILKINS, L.J. Broken Bones in Chickens: Effect of Stunning and Processing in Broilers. British Poultry Science, Cambs, v. 31, n. 1, p. 53-58, jan./fev. 1990.

GROSSKLAUS, D. Inspeción sanitaria de la carne de ave. Zaragoza : Acribia, 1979, $354 \mathrm{p}$.

JULIAN, R.J. "Valgus-Varus" Deformity of the Intertarsal Joint in Broiler Chickens. Canadian Veterinary Journal, Ottawa, v. 25, n. 6, p. 254258, jun. 1984.

KANNAN, G. e MENCH, J.A. Influence of Different Handling Methods and Crating Periods on Plasma Corticosterone Concentrations in Broilers. British Poultry Science, Cambs, v. 37, n. 1, p. 21-31, jan. 1996. 
LEESON, S., SUMMERS, J.D. Some Nutrition Implications of Leg Problems with Poultry. British Veterinary Journal, London, v. 144, n. 1, p. 8192, jan.-fev. 1988.

MULDER, R.W. Nova tecnologia de processamento de aves: aspectos de higiene e meio ambiente. Aves e Ovos, São Paulo, v. 10, n. 6, p. 17-18, abr. 1994.

NEWBREY, J.W., BAKSI, S.N., DHILLON, A.S., ZIMMERMAN, N.G., TRUITT, S.G., RIEDINGER, R. Histomophometry and Vitamin D Metabolism of Valgus-Varus Deformity in Broiler Chickens. Avian Diseases, Kenett Square, v. 32, n. 4, p. 704-712, out.-dez. 1988.

OSOL, A., CHASE, S.W., FRANCIS, C.C., NELLHAUS, G., PRICHARD, R.W., RICHARDSON, R.E., WENGER, N.K. Dicionário Médico Blaskiston, 2. ed. São Paulo: Organização Andrei, 1982. 1169 p.
RIDDELL, C., KING, M.W., GUNASEKERA, K.R. Pathology of the Skeleton and Tendons of Broiler Chickens Reared to Roaster Weights. Avian Diseases, Kennett Square, v. 27, n. 4, p. 980-991, out.-dez. 1983.

SUMMERS, J.D., SHEN, H., LEESON, S., JULIAN, R.J. Influence of Vitamin Deficiency and Level of Dietary Protein on the Incidence of Leg Problems in Broiler Chicks. Poultry Science, Champain, v. 63, n. 6, p. 1115-1121, jun. 1984.

TARDIN, A.C. Visão Nutricional dos Problemas Locomotores em Frangos de Corte. In: Conferência APINCO - Associação Brasileira de Produtores de Pintos de Corte, 1995, Curitiba, p. 71-83.

THORP, B. Transtornos óseos de las aves. Industria Avícola, Mount Morris; v. 41, n. 1, p. 22-24, jan. 1994.

\section{CIETUS}

NIKON (Japão)

Cetus Hospitalar Comércio e Representações Ltda.

Microscópios Biológicos e Industriais - Espectofotômetros Deonizadores - Kits para bioquímica - Contador de Células

\section{Assistência Técnica}

Rua Lopes Trovão, 75 - Benfica 20920-310 - Rio de Janeiro - RJ

Tel.: (21) 568-9345

Fax: (21) 264-3628

E-mail: cetus@abeunet.com.br 